\section{Weed Management in Plasticulture}

\section{A. Richard Bonanno ${ }^{1}$}

Additional index words. vegetable crops, herbicides, cultivation, mulches, row covers

Summary. This review describes the differences in weed management that must be addressed when plastic culture is added to the production cycle. Three specific areas are addressed: weed management under plastic mulch, weed management between plastic mulch, and weed management under row covers.

\section{W} hen producing vegetable crops in field plastic culture, good weed manage ment is as essential as it is in a bare-ground management system. However, weed management strategies are more complex in plasticulture. Fewer chemical options exist, cultivation is difficult, and there is greater potential for crop injury.

\section{Weed management under plastic mulch}

Soil fumigation sometimes is used under plastic mulches. While it is used primarily for disease and nematode control, weed management is also a benefit. Not all weeds, however, are controlled by soil fumigation, and generally sodium methyldithiocarbamate (Vapam) is not as effective as methyl bromide in providing good weed control. To obtain good control of weed seeds, rhizomes, and tubers under the mulch, soil conditions must be favorable. Specifically, soil temperatures should be at least $60^{\circ} \mathrm{F}\left(15^{\circ} \mathrm{C}\right)$, soil moisture should be near field capacity, and seeds and tubers should not bedormant. Two weed types

${ }^{1}$ Senior extension specialist, University of Massachusetts, 255 Merrimack Street, Methuen, MA 018446433.

The cost of publishing this paper was defrayed in part by the payment of page charges. Under postal regulations, this paper therefore must be hereby marked advertisement solely to indicate this fact. that commonly escape soil fumigation are nutsedge (Cyperus sp.) and legumes (clover, vetch, etc.). Nutsedgetubers are usually dormant in early spring even though soil temperatures may be suitable for treatment. Ideally, summer or fall is best for controlling nutsedge tubers with fumigation. Legume seeds seldom are killed by soil fumigation. Legume seedcoats are very hard; fumigation scarifies these seeds and may actually improvetheir germination. Methyl bromideevaporates from the soil in about 2 weeks. Vapam, however, takes at least 4 weeks to evaporate. As a result, Vapam is used best as a summer or fall treatment. In northern areas of the United States, fall application [before the soil temperature drops below $50^{\circ} \mathrm{F}(10$ $\left.{ }^{\circ} \mathrm{C}\right)$ ] combined with spring planting works best for Vapam. Solarization (controlling weed seeds with high temperatures created by clear plastic over the soil) also may be an option in some areas.

Currently, Vapam is registered for use regardless of the crop that will be planted. Methyl bromide, however, is registered for use only on the following field produced vegetable crops: asparagus, broccoli, cantaloupe, cauliflower, eggplant, lettuce, dry bulb onion, pepper, and tomato. Methyl bromide may be applied to plant beds that are used to producetransplants of any crop. Thekey to the methyl bromide registration is that the plants will then be transplanted to a nontreated area.

If Vapam or methyl bromide fumigation is applied under plastic strips, there is generally no need for a herbicide under the plastic. There is usually no need for a herbicide under black plastic, regardless of fumigation. Nutsedge may be the exception because it can germinate under black plastic and grow through it. Some weeds may emerge from the plant holes; this is discussed below. Herbicides are needed under clear or white plastic if thesoil is not fumigated. Colored mulches [including infrared transmitting (IRT) types] also have been used to mimic the soil-warming property of clear plastic while providing the weed suppression of black plastic; however, weeds are not always suppressed adequately. Local experience with colored plastics will determine the need for herbicides.

The following suggestions will help optimize weed control under plastic:

1) Prepare a raised bed or use normal soil preparation if raised beds are not used.

2) Apply the herbicide to the bed or soil surface.

3) Activate the herbicide with rainfall or overhead irrigation [at least 0.5 inch $(1.2 \mathrm{~cm})$ ]; incorporate the herbicide if required and reshape the bed. Incorporating herbicides on raised beds is not always an easy task. Equipment modifications or specialized equipment may be required so that the herbicide is incorporated at the correct depth while not completely destroying thebed. Successful incorporation tools for beds includenarrow rototiller units or rolling cultivators run in tandem over and/or between the beds. Some growers have tried to incorporate herbicides on flat ground and then make raised beds. This practice may stunt crops by mixing the herbicide too deeply into the soil. When the bed is made, soil is thrown from theaisles to the bed center; treated soil is thrown on top of treated soil. For example, a herbicide that was intended to be incorporated to a depth of 4 inches $(10 \mathrm{~cm}$ ) can end up 6 to 8 inches ( 15 to $20 \mathrm{~cm}$ ) deep on a raised bed. When the crop is seeded or transplanted, the crop roots encounter the herbicide to a greater depth than is recommended, often resulting in crop stunting.

4) Apply the plastic mulch. If the herbicide was applied over theentirefield, applying the plastic may destroy theweed barrier adjacent to the plastic strips. Weed management in the row middles is discussed in the next section.

Some herbicides may volatilize and injure crop when used under plastic mulches. Be careful to observe any precautions on the product label and, in the absence of experience, try this practice on a small scale first.

Whereblack plastic or similar mulch is used, weeds may grow in the plant holes only. The question arises as to how competitive theseweeds areand if they interferewith thecrop. Research has shown that differences among crops exist. In results from North Carolina (Monaco and Bonanno, 1988), transplanted tomato yields were not affected, muskmelon yields were $40 \%$ lower, and pepper yields were $73 \%$ lower when no herbicide was applied under black plastic. These results appear to be a direct result of the speed of crop growth and eventual soil shading. Tomatoes grow vigorously after transplanting, whereas peppers grow very slowly the first 2 to 3 weeks after transplanting. Direct-seeded crops probably would have little competitive advantage over the weeds, since crop emergence would be similar in timing to weed emergence and would probably suffer greater yield loss than transplanted crops.

Some researchers have experimented with applying small amounts of herbicide in the transplant water at the time of transplanting (Besteet al., 1993). The amount of herbicide applied would be the same as if a soil application were made to the same size area (plant hole). Calibration in this system would be critical to obtain the correct herbicide rate without injuring the crop plants. It is also unclear whether the herbicide label would need to specify this application technique.

\section{Weed management between plastic mulch strips}

As is the case with bare-ground culture, weeds must be managed successfully between the crop rows. Control may include the use of herbicides and/or cultivation. Timings for herbicide applications includestalebed, preemergence, and postemergence.

Stale bed applications. In many cases, the choices of herbicides for use in vegetable crop 
production are limited. Even when a herbicide is registered for use in a crop, weed species that the herbicidecannot control may bepresent. To obtain some early-season control, paraquat (Gramoxone Extra) or glyphosate (Roundup) may be applied to emerged weeds using the stalebed technique. The steps involved are outlined below:

1) Prepare the field and lay the plastic mulch as far ahead of seeding or transplanting the crop as possible. If a soil-incorporated herbicide will be used on the entire field, it must be applied and incorporated at this time. The soil should have adequate moisture [irrigate with at least 0.25 inch $(0.6 \mathrm{~cm})$ of water if necessary].

2) Wait as long as possible so that weeds will germinateand emergebetween theplastic. Weed seedlings should beall owed to grow to thethird leaf stage; the first true leaf is a minimum stage of growth. In some cases the plastic may be applied several months before transplanting.

3) If transplants are being used, apply paraquat or glyphosate(seelabels) as abanded spray to the row middles before transplanting the crop into the mulch.

4) If the crop will be seeded, the paraquat or glyphosate may be applied just before or just after seeding as long as the crop has not yet emerged (see labels).

Theprinciple of this techniqueis that most of the weeds that can germinate, because of their placement in the soil profile, usually will do so within 2 weeks after soil preparation. Adequate soil moistureand temperature [at least $50^{\circ} \mathrm{F}\left(10^{\circ} \mathrm{C}\right)$ at a depth of 2 inches $(5 \mathrm{~cm})$ ] must be present. Paraquat or glyphosatewill kill theseweeds. Alack of further disturbance of the soil surface will result in no movement of additional weed seeds to the soil surface. This technique also will improve the performance of any residual herbicides applied, since a reduced number of viable weed seeds will be near the soil surface. Remember that neither paraquat nor glyphosate will provide any residual weed control. Check current labels to determine if paraquat or glyphosateis registered for usein each crop. For cucumber, melon, squash, pumpkin, pepper, and eggplant, glyphosate must be applied at least 3 days before seeding or transplanting. In cases where glyphosate is labeled, it also can be used for controlling suppressing perennial weeds, which may haveemerged. Finally, any cultivations should be performed as shallowly as possible [0.75 to 1 inch $(1.9$ to $2.5 \mathrm{~cm}$ ) maximum] so as not to reposition any additional weed seeds.

Some special precautions are in order with glyphosate. If glyphosate is used as a broadcast application or if excessive glyphosate comes in contact with the plastic mulch, overhead irrigation or rainfall is required before planting to wash the excess glyphosate off the plastic. Glyphosate does not photodegrade to any great extent while on the surface of the plastic. It is also very water soluble. There have been numerous occasions in which glyphosate from the mulch surface was washed by the transplant water into the plant hole at the time of transplanting. Since glyphosate is inactivated by clay and since most transplants areproduced in soilless mixes with no clay, the roots of thetransplants will absorb the glyphosate. This scenario has resulted in crop injury or death. Injury appears as blotchy chlorosis followed by necrosis and/or virus-like symptoms. This situation is also possible with paraquat, although paraquat photodegrades. Research (Gilreath and Duranceau, 1986) showed that transplanting should be delayed at least $96 \mathrm{~h}$ after applying paraquat to mitigate the injury potential. The best way to avoid this situation altogether is to apply the herbicide carefully to the row middles and avoid the plastic.

Residual herbicides. Residual herbicides often are recommended for weed control between plastic mulches. Depending on the crop, preplantincorporated and/or preemergenceherbicides may be labeled. Both types of applications require some precautions.

If a preplant-incorporated herbicide is used, it must be applied and incorporated before applying the plastic mulch, since incorporating a herbicide into the row middles is very difficult. This creates a problem, especially if beds are used. Without specialized equipment that can incorporate the herbicide to the proper depth while not significantly destroying the beds, many growers avoid these herbicides. Some of these herbicides, such as clomazone or bensulide, must be very shallowly incorporated to avoid crop injury and to be effective. Care must be taken to maintain a herbicide layer next to the plastic strips. Also, proper incorporation is much easier if raised beds arenot used. As mentioned earlier, two of the most successful types of incorporation tools on beds are either narrow rototiller units or rolling cultivators run in tandem over and/or between the beds.

Use only a labeled preemergence herbicide between the plastic strips, before or after planting. Using nonlabeled herbicides may result in crop injury or death from either the herbicide moving with water under the plastic or from the crop roots growing past the edges of the plastic; such use is illegal. Also, do not spray the surface of the plastic with residual herbicides. The excess herbicide around theplant holes can wash into the holes with rain or irrigation, greatly concentrating the herbicide and potentially causing crop stunting, injury, or death. Application booms must be set up to band the herbicide between the plastic; growers often try to lap the spray onto the plastic 1 to 2 inches $(2.5$ to $5 \mathrm{~cm}$ ) to avoid lack of application to soil along the plastic's edges.

When banded applications of herbicides are used, remember to calculate the actual area of soil that is being sprayed per acre of crop. Wwith $30 \mathrm{inch}$ $(76 \mathrm{~cm})$ beds and 30 inch $(76 \mathrm{~cm})$ middles, for example, only half the total amount of herbicide would be required per acre since only half the amount of soil areaper acreis actuallybeing sprayed. Follow label directions for banded applications.
In some cases, combinations of herbicides may be used to increase the weed control spectrum. In tomato, for example, trifluralin (Treflan) may be incorporated over the entire field before applying theplastic mulch, and metribuzin (Sencor or Lexone) may be applied to the row middles after transplanting. Note that herbicidelabels generally do not mention the use of plastic mulches unless the use is not allowed or precautions are necessary. Unless the label specifies otherwise, herbicides can be used in combination with plasticulture as long as all label directions are followed, including herbicide rate, placement, timing, and crop planted.

A common problem with small growers is the diversity of crops that may be grown in a small area with different crops in adjacent rows. In this case, the stale bed method may be encouraged, whereas using residual herbicides may be limited. Growers should try to group crops based on herbicide registrations. Also, some herbicides that are registered for useon only oneor two crops may not be able to be used. For example, napropamide could be used in an area where pepper, tomato, eggplant, cabbage, cauliflower, and broccoli will be grown in adjacent rows. Using metribuzin (Sencor or Lexone) for additional broad-leaf weed control in tomato might not be possible if the tomatoes aregrowing along arow middlecommon to one of the other crops. If several rows of tomatoes are grown, metribuzin could be used in all but the common row middles.

Postemergence applications. For several vegetable crops, postemergence herbicides are registered. These may include selective herbicides such as metribuzin or sethoxydim (Poast) and limited registration of the nonselective herbicide, paraquat. One disadvantage of many postemergence herbicides is that they have no residual activity, thus requiring repeated applications. It is advisable to usearesidual herbicidein most cases and to supplement it with a postemergence application if it is labeled and needed.

For selective herbicide use, the same precautions apply as for the surface-applied herbicides mentioned in the previous section. These include banding the herbicide between the plastic and minimizing contact with the plastic to avoid runoff into the plant holes. Other than these precautions, the same precautions must be followed for the use of any postemergence herbicide in bare ground culture.

In many states and for certain crops, paraquat is registered for use between plastic mulch while the crop is present.These uses are much more limited than the broad stale bed registrations described previously; however, many state registrations exist beyond those that are on the national label. Special care must be taken with paraquat to avoid crop injury. In all cases, paraquat must be applied with a shielded sprayer to the row middle. Contact with the crop may cause necrosis of that crop part within $24 \mathrm{~h}$. For example, if the runner 
from a cucumber plant is sprayed with paraquat, the runner will die. There will, however, be no translocation back to the rest of the plant. When building or using ashield, theseguidelines should be followed. Shield the spray, not the crop. A full shield (top, front, back, sides) is preferred over traditional shields, which only protect on thesides. The shield should be slightly wider than the row middle so that no skips aremadeal ong the plastic. Since the shield should be used slightly above the plastic to avoid tearing the plastic, an apron should hang below the shield on all sides as a flexible buffer for the spray. Plastic film or some other nonabsorbent material is used for the apron. Burlap or other fabrics should be avoided; they will absorb the paraquat and act as a wick applicator, causing crop injury. Even with a shield, windy conditions should be avoided. The best shields will still allow some movement of herbicide past the shield.

Under no circumstances should glyphosate be used between the plastic during the season. Glyphosate is a nonselective and translocated herbicide. Contact with thetip of that samecucumber runner described above may result in death of the entire cucumber plant. Glyphosate should be used only as a stale bed treatment or after the crop is harvested, if needed, for controlling perennial weeds. As shielding technology changes, the restrictions on glyphosate also may change. Other herbicides also are available or are being developed and may be used for postemergence weed control between mulches. Consult labels and recommendations to be advised of potential use and rate changes.

Backpack sprayers or hand-held boom sprayers often are used for herbicide applications in plasticulture systems. Be sure to calibrate them properly and maintain a constant pressure by monitoring a pressure gauge, especially on handpumped models. Use caution when spraying paraquat with a backpack or hand-held sprayer; follow all of the precautions and restrictions on the label. Spray when the wind is calm to avoid spray drift to crop plants. Always use a surfactant and sufficient water with paraquat to obtain good control.

Cultivation. Cultivation is used by some growers to control weeds in the row middles. Some factors need to be considered. Cultivation equipment should be narrow, and high clearance tractors should be used. Growers without these tools often leave wide row middles to allow a tractor to pass between the rows of plastic. This results in row middles of 6 to 10 feet $(1.8$ to $3 \mathrm{~m})$ or more compared to row middles of 2 to 3 feet $(0.6$ to $0.9 \mathrm{~m}$ ), which is common when herbicides or specialized cultivation tools are used. Leaving a strip of weeds along the plastic is not acceptable. Cultivation equipment should be designed to cultivate to the edge of the plastic while not tearing it. The most successful tools are designed to lift the mulch slightly, to shallow cultivate just under it, and to add soil back to cover the edge of the plastic. In all cases, weeds should be cultivated when they are very small. When weeds are small, they can be buried by the action of the cultivator as well as being cut or uprooted. Finally, never cultivate more rows than were applied by a single pass of a plastic mulching machine. Guess middles (row middles created between passes of equipment) are rarely consistent in width, and excessive tearing of the plastic or uncultivated areas can result.

Much research has been conducted concerning the influence of weeds in the row middles on crop yield and quality. The question most often asked is whether the combination of plastic mulch, under-plastic fertilizer, and drip irrigation can compensatefor pressurefrom weeds in therow middles. In one series of studies, the influence of weeds in row middles was evaluated in pepper (Bonanno, 1988; Monaco and Bonanno, 1987), tomato (Bonanno, 1987; Monaco and Bonanno, 1986), and muskmelon (Bonanno, 1989; Monaco and Bonanno, 1988). Overhead irrigation and drip irrigation also were compared in pepper and tomato grown on plastic mulch. On average, weeds in therow middles reduced yield $25 \%$ to $30 \%$ in all threecrops with overhead irrigation/plastic mulch, and $55 \%$ to $60 \%$ in tomato and muskmelon with drip irrigation/plastic mulch compared to the best herbicidetreatment for each crop. Oneexplanation for this difference might be that, when overhead irrigation is used, the roots of the weeds are well spread over the field (under and between the plastic). When drip irrigation is used, especially in a dry year, most weed roots are close to the drip tube and are competitive with the crop, which also has its roots in the same area. In another study conducted with tomato over 3 years, weeds in the row middles reduced yield 75\% (Teasdale and Colacicco, 1985). In this study, no supplemental irrigation was applied, since adequate soil moisture was present during each growing season.

As an alternative to cultivation and residual herbicides, some growers have tried planting a cover crop in the rowmiddles. Success has been very limited with this option. However, if the cover is more competitive than the weeds it will reduce yields at least as much as the weeds. There are at least two possibilities to try to avert the competition.

1) Apply the plastic mulch long enough before planting to establish a thick cover in the row middles. Before planting, desiccate the cover with glyphosate or paraquat and rely on the dead cover to suppress the weeds; if the cover is thick enough, it may suppress weeds.

2) Plant the cover at the same time the crop is planted, and to rely on mowing to suppress the cover. This will not eliminate the competition but will reduce it. Advantages of this system are improved trafficability and reduced soil erosion. Several growers, however, have reported that mowing is time-consuming and hard on equipment. While still an option for some, many growers who have tried mowing have abandoned this technique. Note that cover crop selection varies with location; consult local experts to determine which cover crops will grow best in agiven area. Winter hardiness also may be a factor in cover crop selection.

\section{Weed management under rowcovers}

Rowcovers (single and multiple row widths) sometimes are used by growers just after planting acrop during cool weather. They result in warming of the soil and theair around thecrop. From aweed management standpoint, this warmer environment contributes to early germination of weed seeds and rapid growth of weeds once they emerge. It is not uncommon to see lush weed growth under a rowcover and no weed growth between the covers. Row overs can create serious problems for growers who rely on cultivation for weed control. By the timetherowcover is removed, theweeds may beso large that hand-weeding may be the only option available.

When using herbicides to manage weeds under rowcovers, several points should be considered. From an application and activation standpoint, the same information described above for use of herbicides under plastic mulch applies. The only noteworthy differences areas follows. If fabric rowcovers that allow rainfall and irrigation to move freely through the cover are used, surface-applied herbicides could be activated after the cover is applied. The only advantage here is that the field can be prepared, the crop seeded or transplanted, the herbicide applied, and the rowcover applied all in rapid succession. Oncethe rowcover is applied, the field can be irrigated. Another difference to consider is that weed emergence will be slow between the rowcovers, in many cases affording some additional time before a row middle treatment is required. In both cases, it is important to pay close attention to weed emergence patterns so that poor weed control caused by a herbicide application or activation that is too late can be avoided.

Herbicide use under rowcovers can be dangerous. Although several herbicides can be used safely under rowcovers, some uses can cause or contribute to crop injury and even crop death. Generally, ventilated (perforated, slitted, or fabric) rowcovers aresafer from an herbicideinjury standpoint than solid rowcovers or hot caps. This is especially true with a herbicide that is moderately or highly volatile. Prior testing on a small scale is strongly recommended before making these applications on a large scale. In one case, use of ethalfluralin (Curbit) is prohibited by the label under mulches and rowcovers due to the potential for crop injury. Remember that improper uses of some rowcovers can, by themselves, cause crop injury. For example, many cultivars of sweet corn, especially supersweets and sugar-enhanced, do not germinate well in cold soils. When a grower 
plants corn in cold soils and then places a rowcover over the rows, poor germination and emergencestill can result. Under cloudy conditions, the soil does not warm fast enough, and the corn seed imbibes cold water, which will slow germination. While the herbicides do not cause the problem, they can accentuate it. If soil temperature is adequateand rowcovers areventilated, the likelihood of crop injury is greatly reduced. Another example involves high temperatures. Although solid clear tunnels are excellent for rapid soil warming, excessive air temperatures under the cover can kill the crop. This can result regardless of whether or not aherbicidewas used. It is important to monitor air temperatures under rowcovers and ventilate or remove rowcovers if air temperature becomes extreme [e.g., $\left.100^{\circ} \mathrm{F}\left(38^{\circ} \mathrm{C}\right)\right]$.

In conclusion, weed management in plasticulture requires ahigher level of management than bare-ground culture. Observing all of the guidelines above will go a long way to ensure effective weed control with minimal adverse crop effects.

\section{Literature Cited}

Beste, C.E., J.P. Donohoe, and D.A. Dinkel. 1993. Herbicides in transplant water for mechanical pot planters in plastic mulch. Proc. Weed Sci. Soc. Amer. 33:21.

Bonanno, A.R. 1987. Influence of oxyfluorfen and cinmethylin on weed control, yield, and quality of tomatoes grown in plastic culture. Proc. Southern Weed Sci. Soc. 40:121.

Bonanno, A.R. 1988. Influence of oxyfluorfen, cinmethylin, and glufosinate on weed control, yield, and quality ofpepper. Proc. Weed Sci. Soc. Amer. 28:70.

Bonanno, A.R. 1989. Influence of oxyfluorfen, cinmethylin, ethalfluralin, and glufosinate on weed control and yield of muskmelons grown in plastic culture. Proc. Weed Sci. Soc. Amer. 29:26-27.

Gilreath, J.P. and S.J. Duranceau. 1986. Photodegredation of paraquat applied to polyethylenefilm mulch. Proc. Southern Weed Sci. Soc. 39:178.

Monaco, T.J. and A.R. Bonanno. 1986. Herbicide evaluations in horticultural crops. Hort. Crops Res. Ser. 72:1-226.

Monaco, T.J. and A.R. Bonanno. 1987. Herbicide evaluations in horticultural crops. Hort. Crops Res. Ser. 75:1-197.

Monaco, T.J. and A.R. Bonanno. 1988. Herbicide evaluations in horticultural crops. Hort. Crops Res. Ser. 80:1-180.

Teasdale, J.R. and D. Colacicco. 1985. Weed control systems for fresh market tomato production on small farms. J. Amer. Soc. Hort. Sci. 110:533-537.

\section{Fumigation and Solarization Practice in Plasticulture Systems}

\section{James J. Stapleton ${ }^{1}$}

Additional index words. soil

disinfestation, methyl bromide,

biofumigation, biological control, intensive

agriculture, solar heating

Summary. Soil disinfestation strategies for intensive vegetable crop production, which have relied heavily on chemical fumigants for the past 40 years, are now undergoing rapid change. The principal driving force of change has been governmental regulatory action to phase out chemicals with properties deemed to be hazardous to the environment and/or public health. Softer methods of soil disinfestation, which rely more on physical, cultural, biological, or integrated modes of action, likely will predominate in future vegetablecropping systems. In conducive (i.e., warm) climates, solarization can be adopted economically in plasticulture systems. Solarization can be combined with other chemical, physical, and biological methods for enhanced management of soil and root pests and diseases.

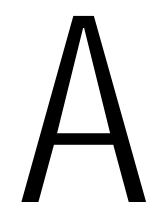
gricultural production systems using plasticulture are necessarily those of intensively managed, high-value crops. Sophisticated microirrigation systems, including surface or subsurface drip, often are used in this type of production. The input costs are high, and production quantity and quality must be maximized to recoup the risk capital involved. In

'IPM specialist, Statewide Integrated Pest Management Project, Kearney Agricultural Center, University of California, Parlier, CA 93648.

The cost of publishing this paper was defrayed in part by the payment of page charges. Under postal regulations, this paper therefore must be hereby marked advertisement solely to indicate this fact. many cases, land used for this type of agriculture is in use almost constantly, with one or several crops planted and harvested each year. The land may not be rested periodically, and production costs may be too high to allow for soil-building rotations or cover crops to fit into the schedule. Under these conditions, inoculum of soil-borne diseases (caused by fungi, bacteria, viruses, and nematodes) and pests (including insects and weed propagules) may build up in sufficient numbers to threaten the high-value crops with economically catastrophic damage.

\section{Recent history of soil disinfestation}

Under intensive crop cultivation, soil disinfestation may provide the difference between reasonable profit and total crop loss. For the past 50 years, the chemical soil disinfestants have allowed such intensivecropping schemes to exist. Coming into widespread use after World War II, and using many compounds generated as byproducts of the war effort, farmers reaped the benefits of highly effective, relatively inexpensive soil disinfestants such as 1,2-dichloropropane/ 1,3-dichloro-propene (D-D mixture), methyl bromide, chloropicrin, ethylenedibromide (EDB), and others (Newhall, 1955). Interest and practice in older, nonchemical strategies for managing soilborne pest problems waned as the new fumigant compounds provided what seemed to bethelongsought-after magic bullet treatment. Hand in hand with new fertilizer formulations, which provided plants with optimal fertility levels, the readily available soil fumigant chemicals allowed a tremendous upward leap in crop productivity (Johnson and Feldmesser, 1987).

After 30 years of continual use, however, problems began to arise in the mid-1970s from overdependence on chemical fumigants, particularly in the irrigated valleys of the arid western United States. Due to the sheer volume of fumigant chemicals that had been poured into the sandy desert soils, accumulations of these products entered into the groundwater reserves and began to show up in drinking-water supplies in several metropolitan areas. In addition, public sentiment was stirred by reports of worker illnesses and deaths in United States facilities manufacturing fumigants such as DBCP and EDB. Governmental regulatory actions began to take effect and several fumigant chemicals were forced off the market. Intensive agriculture soon found itself in a situation in which only afew chemical soil disinfestants remained available, and efforts are underway to limit or phase out those that do remain on the market (Grossman and Liebman, 1995; Stapleton and DeVay, 1995).

\section{Soil fumigation}

Methyl bromide is widely considered to be the best chemical soil fumigant, providing excel- 